\title{
Lithium-induced Downregulation of Aquaporin-2 Water Channel Expression in Rat Kidney Medulla
}

\author{
David Marples, Sten Christensen, ${ }^{\star}$ Erik Ilso Christensen, Peter D. Ottosen, ${ }^{\star}$ and Soren Nielsen \\ Department of Cell Biology, Institute of Anatomy, University of Aarhus, DK-8000 Aarhus; *Department of Pharmacology, University \\ of Copenhagen, DK-2200 Copenhagen; and ${ }^{\ddagger}$ Institute of Pathology, Randers Hospital, DK-8900 Randers, Denmark
}

\begin{abstract}
Lithium, a widely used treatment for bipolar affective disorders, often causes nephrogenic diabetes insipidus. The effect of chronic lithium therapy on the expression of the vasopressin-regulated water channel Aquaporin-2 (AQP2) in rat kidney was examined. Membranes were prepared from inner medulla of one kidney from each rat, while the contralateral one was fixed for immunofluorescence and immunoelectronmicroscopy. Immunoblotting revealed that lithium treatment reduced AQP2 expression dramatically, to $31 \pm 8 \%$ after $10 \mathrm{~d}$ and to $4 \pm 1 \%$ after $25 \mathrm{~d}$, coincident with development of severe polyuria. Immunofluorescence and immunogold quantitation confirmed the lithium-induced decrease in AQP2 expression (from $11.2 \pm 1.0$ to $1.1 \pm 0.2$ particles $\left./ \mu \mathrm{m}^{2}\right)$. The downregulation was only partly reversed by return to lithium-free diet for 1 wk $(\mathbf{4 0 \pm 8 \%}$ of control). Furthermore, immunoblotting and immunogold quantitation revealed that $2 \mathrm{~d}$ of thirsting or $7 \mathrm{~d}$ of dDAVP treatment, in the continued presence of lithium, increased AQP2 expression by six- and threefold, respectively, coincident with increased urinary osmolality. Thirsting increased AQP2 immunolabeling mainly of vesicles, whereas dDAVP caused accumulation of AQP2 predominantly in the subapical region and plasma membrane. Thus, lithium causes marked downregulation of AQP2 expression, only partially reversed by cessation of therapy, thirsting or dDAVP treatment, consistent with clinical observations of slow recovery from lithium-induced urinary concentrating defects. ( $J$. Clin. Invest. 1995. 95:1838-1845.) Key words: vasopressin • nephrogenic diabetes insipidus • collecting duct $\bullet$ membrane trafficking • water balance
\end{abstract}

\section{Introduction}

Lithium salts are prescribed to 1 in 1,000 of the population for the management of affective disorders, particularly manicdepressive illness (1). One of the most common side effects of this treatment is polyuria, caused primarily by a vasopressinresistant urinary concentrating defect, i.e., nephrogenic diabetes

Address correspondence to Søren Nielsen, MD, PhD, Department of Cell Biology, Institute of Anatomy, University of Aarhus, DK-8000 Aarhus, Denmark. Phone: 8942-3046; FAX: 8619-8664; E-mail: SN@ANA.AAU.DK.

Received for publication 17 October 1994 and in revised form 8 December 1994.

J. Clin. Invest.

(C) The American Society for Clinical Investigation, Inc. $0021-9738 / 95 / 04 / 1838 / 08 \quad \$ 2.00$

Volume 95, April 1995, 1838-1845 insipidus (NDI) ${ }^{1}(2)$. This may affect up to $50 \%$ of patients on lithium (3), although it is clinically significant to only about $20 \%$ (3). However, this represents substantial morbidity associated with a common treatment. The extent to which this side effect is reversible after cessation of lithium therapy is also in debate (4).

There is now considerable evidence that lithium inhibits the action of the antidiuretic hormone vasopressin, although the mechanism of this inhibition is not yet clear (3). It has been suggested that lithium acts by inhibiting adenylate cyclase activity in the collecting duct principal cells $(2,5)$, thus preventing the production of cAMP, the second messenger for vasopressin. Prostaglandins may (6) or may not (7) play a part in this inhibition.

Recently the gene for Aquaporin-2 (AQP2), a member of the Aquaporin family of water channels (8), was identified and sequenced (9), and several studies strongly support the view that $\mathrm{AQP2}$ is the predominant vasopressin-sensitive water channel of the renal collecting duct. AQP2 is selectively localized in the collecting duct principal cells $(9,10)$, mainly in the apical plasma membrane and intracellular vesicles (10). Recent evidence suggests that vasopressin acutely increases the water permeability of the collecting ducts by stimulating insertion of AQP2 water channels from intracellular vesicles into the apical plasma membrane $(11,12)$. The expression of $A Q P 2$ is increased by dehydration or chronic vasopressin administration $(10,13)$, representing a long-term regulatory mechanism in antidiuresis. Detailed studies have revealed that mutations in AQP2 can cause severe NDI (14), demonstrating that AQP2 is necessary for urinary concentrating ability.

The effect of chronic lithium therapy on AQP2 expression in rat kidney may provide physiological and pathophysiological information about water balance and water balance disorders. Acquired NDI is more common than the primary form, and, although a number of conditions and pharmacological agents are known to cause acquired NDI (15), the molecular basis remains elusive. Furthermore, correction of urinary concentrating ability lags significantly behind the correction of the primary abnormality in a number of water balance disorders (for review see reference 13). These issues are also addressed in this study.

In summary, this study shows that chronic lithium treatment downregulates AQP2 expression in parallel with the development of severe diabetes insipidus. This effect is only partially reversed by thirsting, intravenous 1-desamino-8-D-arginine-vasopressin (dDAVP), or return to a lithium-free diet, consistent with clinical findings in lithium-treated patients, including slow recovery of urinary concentrating ability after lithium therapy.

1. Abbreviations used in this paper: AQP2, Aquaporin-2; dDAVP, $1-$ desamino-8-D-arginine-vasopressin; NDI, nephrogenic diabetes insipidus. 


\begin{tabular}{|c|c|c|c|c|c|c|c|}
\hline Group & $n$ & Body weight & $\begin{array}{c}\text { Water } \\
\text { drinking }\end{array}$ & $\begin{array}{c}\text { Urine } \\
\text { osmolality }\end{array}$ & $\begin{array}{c}\text { Plasma } \\
\text { osmolality }\end{array}$ & $\begin{array}{l}\text { Plasma } \\
\text { lithium* }\end{array}$ & AQP2 expression \\
\hline & & $g$ & $m / 24 h$ & mosmolkg $\mathrm{H}_{2} \mathrm{O}$ & mosmolkg $\mathrm{H}_{2} \mathrm{O}$ & $m M$ & percentage of controls \\
\hline \multirow[t]{3}{*}{ Controls } & 5 & $290 \pm 1.5(10 \mathrm{~d})$ & & & & & \\
\hline & 5 & $358 \pm 10.0(25 \mathrm{~d})$ & $43 \pm 2$ & $1,266 \pm 274$ & $310 \pm 3.7$ & $0.00 \pm 0.004$ & 100 \\
\hline & 5 & $399 \pm 8.3(35 \mathrm{~d})$ & & & & & \\
\hline Lithium $10 \mathrm{~d}$ & 10 & $226 \pm 2.6$ & $87 \pm 11$ & $388 \pm 48$ & $404 \pm 28$ & $0.99 \pm 0.04$ & $31 \pm 8$ \\
\hline Lithium $25 \mathrm{~d}$ & 10 & $260 \pm 6.3$ & $187 \pm 20$ & $223 \pm 59$ & ND & ND & $4 \pm 1$ \\
\hline Lithium $35 \mathrm{~d}$ & 10 & $279 \pm 7.7$ & $288 \pm 14$ & $177 \pm 11$ & $314 \pm 5$ & $1.31 \pm 0.14$ & $10 \pm 3$ \\
\hline Lithium $34 \mathrm{~d}$, thirsted last $48 \mathrm{~h}$ & 11 & $189 \pm 4.9$ & $281 \pm 9^{\ddagger}$ & $944 \pm 126$ & $397 \pm 8.3$ & $1.09 \pm 0.16$ & $45 \pm 7$ \\
\hline Lithium $35 \mathrm{~d}$, dDAVP last $7 \mathrm{~d}$ & 8 & $230 \pm 10.7$ & $90 \pm 26$ & $1,115 \pm 561$ & $313 \pm 4$ & $2.11 \pm 0.22$ & $11 \pm 5$ \\
\hline Reversal $7 \mathrm{~d}$ & 5 & $303 \pm 6.4$ & ND & $836 \pm 128$ & ND & ND & $40 \pm 8$ \\
\hline
\end{tabular}

Body weight, urine and plasma osmolality, and plasma lithium were determined at the time of killing, water drinking over the previous $24 \mathrm{~h}$, or ${ }^{\ddagger}$ before thirsting. Values are expressed as mean \pm standard error. There were no significant differences between control groups except for body weight, and results were pooled. Treatment with lithium caused weight loss relative to age-matched controls. Although in the first $10 \mathrm{~d}$ this is probably partly due to dehydration, it is mainly attributable to food aversion, previously described as a side effect of lithium (Christensen, S., personal communication). Urine osmolality fell, and water drinking increased relative to controls. After the first $10 \mathrm{~d}$, plasma osmolality normalized, and rats started to gain weight, albeit at only half the rate seen in controls. Thirsting for $48 \mathrm{~h}$, intravenous dDAVP, and return to a non-lithiumcontaining diet all led to an increase in urine osmolality to values not significantly different from controls. In the case of thirsted rats, the increase in urine osmolality was accompanied by a rise in plasma osmolality. * Plasma lithium concentration was in the recommended human therapeutic range $(0.8-1.3 \mathrm{mM}$ [29]), with the exception of the dDAVP-treated group in which plasma lithium was increased, consistent with the known ability of dDAVP to decrease lithium excretion (for review see reference 30 ). $N D$, not determined.

\section{Methods}

Experimental animals. Male Wistar rats, initially weighing $250 \mathrm{~g}$, were obtained from Møllegaard Breeding Centre Ltd. (Ejby, Denmark). Before treatment, rats had free access to standard rat chow and water. For lithium therapy, lithium chloride was added to the chow to give a concentration of 40 or $60 \mathrm{mM}$ lithium/ $\mathrm{kg}$ of dry food. Rats received food containing $40 \mathrm{mM} / \mathrm{kg}$ for the first $10 \mathrm{~d}$ and then $60 \mathrm{mM} / \mathrm{kg}$ thereafter; this protocol results in serum lithium at therapeutic levels and minimizes the weight loss caused by lithium, as described in detail previously (16). All rats on lithium therapy also had access to a salt block. Water drinking was monitored continuously, and urine output and osmolality were determined on the day before killing, thirsting, or osmotic minipump implantation.

Experimental protocol. The following protocols were followed: protocol $1,10 \mathrm{~d}$ on lithium-containing food ( $n=10$ rats); protocol 2,25 $\mathrm{d}$ on lithium-containing food ( $n=10 \mathrm{rats}$ ); protocol $3,35 \mathrm{~d}$ on lithiumcontaining food ( $n=10$ rats); protocol 4, $28 \mathrm{~d}$ on lithium-containing food, followed by $7 \mathrm{~d}$ with dDAVP, administered intravenously by osmotic minipump, rats continued to receive lithium-containing food ( $n$ $=8$ rats); protocol $5,32 \mathrm{~d}$ on lithium-containing food, followed by 2 $\mathrm{d}$ thirsting, rats continued to receive lithium-containing food $(n=11$ rats); protocol 6, $35 \mathrm{~d}$ on lithium-containing food, followed by $7 \mathrm{~d}$ on normal food ( $n=5$ rats); and protocol 7, control rats were on lithiumfree diet for corresponding periods of time, $10 \mathrm{~d}(n=5 \mathrm{rats}), 25 \mathrm{~d}$ ( $n$ $=5$ rats $)$, and $35 \mathrm{~d}(n=5$ rats $)$. There were no significant differences between groups of any parameters except weight, and consequently results were pooled (Table I).

Implantation of osmotic minipumps. For implantation of the minipumps, pumps (Alzet Co., Palo Alto, CA) were filled with dDAVP in a carrier solution containing $5 \%$ dextrose and $0.05 \%$ acetic acid (13), fitted with silastic cannulae, and equilibrated with normal saline for 4 $\mathrm{h}$ before insertion. Under these conditions, the pumps delivered 0.1 $\mu \mathrm{g} / \mathrm{h}$ of dDAVP. Rats were anesthetized with intraperitoneal sodium pentobarbital, $75 \mathrm{mg} / \mathrm{kg}$, and the cannula was inserted into the left external jugular vein. The pump was tunneled under the skin of the back, and the incision was closed with 4/0 mersilene.

Tissue preparation. For removal of kidneys, rats were anesthetized with intraperitoneal sodium pentobarbital and perfused retrogradely via the aorta as described previously $(10,17)$ with ice-cold PBS $(7.2 \mathrm{mM}$ $\mathrm{Na}_{2} \mathrm{HPO}_{4}, 2.8 \mathrm{mM} \mathrm{NaH} \mathrm{PO}_{4}, 150 \mathrm{mM} \mathrm{NaCl}, \mathrm{pH} \mathrm{7.4)}$. After $3 \mathrm{~min}$, the right kidney was clamped and removed for preparation of crude membrane fractions. The perfusion was immediately changed to cold fixative ( $8 \%$ paraformaldehyde in $0.1 \mathrm{M} \mathrm{Na}$ cacodylate buffer, $\mathrm{pH} 7.4$ ) and continued for a further $3 \mathrm{~min}$. The left kidney was then removed for immunocytochemical localization studies. This procedure was followed for at least 6 rats in each of the protocols 1-5 and 7. Where tissue was not required for immunocytochemistry, the tissue from both kidneys was pooled and used for preparation of membranes.

Preparation of membranes and gel samples. The inner medulla was dissected from each kidney, minced finely, and homogenized in $10 \mathrm{ml}$ of dissecting buffer ( $0.3 \mathrm{M}$ sucrose, $25 \mathrm{mM}$ imidazole, $1 \mathrm{mM}$ EDTA, $\mathrm{pH} 7.2$, and containing the following protease inhibitors: $8.5 \mu \mathrm{M}$ leupeptin, $1 \mathrm{mM}$ phenylmethyl sulfonylfluoride) with five strokes of a motordriven Potter-Elvehjem homogenizer, at $1,250 \mathrm{rpm}$. This homogenate was centrifuged at 4,000 g (L8M; Beckman Instruments, Inc., Fullerton, CA) for $15 \mathrm{~min}$ at $4^{\circ} \mathrm{C}$. The pellet was rehomogenized with three strokes, and the centrifugation was repeated. The supernatants were pooled and centrifuged at $200,000 \mathrm{~g}$ for $1 \mathrm{~h}$. The resultant pellet was resuspended in $\sim 100 \mu$ l of dissecting buffer and assayed for protein concentration using the method of Lowry. Gel samples (in 2\% SDS) were made from this membrane preparation to a final concentration of $1 \mu \mathrm{g}$ of pro$\operatorname{tein} / \mu \mathrm{l}$.

Electrophoresis and immunoblotting. Samples of crude membranes from inner medulla were loaded at $1 \mu \mathrm{g} / \mathrm{lane}$ onto $12.5 \%$ PhastGel SDS-PAGE gels, and run on a PhastGel system, using standard buffer blocks (Pharmacia LKB Biotechnology, Uppsala, Sweden), and transferred to nitrocellulose paper by electroelution. After blocking for $1 \mathrm{~h}$ with PBS $\left(80 \mathrm{mM} \mathrm{Na} \mathrm{HPO}_{4}, 20 \mathrm{mM} \mathrm{NaH} \mathrm{PO}_{4}, 100 \mathrm{mM} \mathrm{NaCl}, \mathrm{pH}\right.$ 7.5 ) containing $0.1 \%$ Tween 20 (PBS-T) containing $1 \%$ bovine serum albumin, blots were washed with PBS-T $(1 \times 15 \mathrm{~min}+2 \times 5 \mathrm{~min})$ and incubated with antibody raised against the $\mathrm{COOH}$-terminal 22 amino acids of AQP2 (either serum, diluted 1:1,000, or affinity-purified with the immunizing peptide, diluted to $40 \mathrm{ng} \mathrm{IgG} / \mathrm{ml}$ ) for $1 \mathrm{~h}$. After washing as above, the blots were incubated with horseradish peroxidase-conjugated secondary antibody (P448; DAKO, Copenhagen, Denmark, di- 


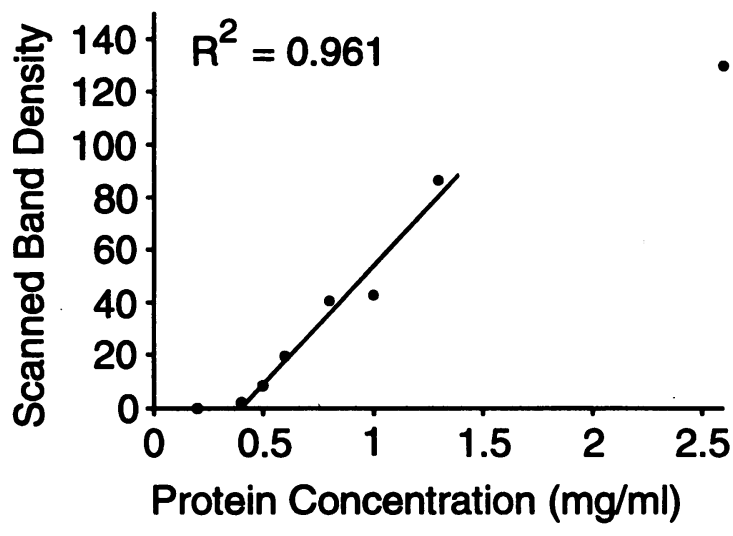

Figure 1. Correlation between sample concentration and scanned band density. Serial dilutions of a sample of membrane protein from inner medulla were run on a gel, and AQP2 was quantitated as described in Methods. The linear regression line was calculated for samples 2-7, and the linear correlation is highly significant $(P<0.001)$.

luted 1:3,000). After a final washing as above, antibody binding was visualized using the enhanced chemiluminescence (ECL) system (Amersham International, Buckinghamshire, United Kingdom). Controls were made with exchange of primary antibody to antibody preabsorbed with immunizing peptide ( $250 \mu \mathrm{g}$ per $40 \mathrm{ng} \mathrm{IgG)}$ ) or with preimmune serum (diluted 1:1,000). All controls were without labeling. ECL films were scanned (Scanjet; Hewlett-Packard Co., Palo Alto, CA) and quantitated using specially written software (available upon request). Bands from gels made with serial dilutions of protein from inner medulla, processed as above, were found to be linear over a wide range (Fig. 1). For quantitation of AQP2 expression, ECL exposures were chosen that gave bands in the control samples that were close to the top of the linear range.

To compare AQP2 levels in the control groups, gels were run with samples from untreated rats in the age groups corresponding to protocols 1-6 $(n=5$ rats in each of 3 groups); no significant differences in AQP2 expression were found between groups.

Preparation of tissue for immunocytochemistry. Tissue blocks prepared from the kidney inner medulla were post-fixed for $2 \mathrm{~h}$ and infiltrated with $2.3 \mathrm{M}$ sucrose $/ 2 \%$ paraformaldehyde for $30 \mathrm{~min}$. Blocks were mounted on holders and rapidly frozen in liquid nitrogen. Thin $(0.85 \mu \mathrm{m})$ and ultrathin $(80 \mathrm{~nm})$ cryosections, cut on a Reichert Ultracut FCS (Reichert, Vienna, Austria), were incubated with affinity-purified antibodies against AQP2 (100-800 $\mathrm{ng} I g G / \mathrm{ml})$. The labeling was visualized as previously described $(10,17)$ using horseradish peroxidaseconjugated secondary antibodies for light microscopy, fluorescein-conjugated secondary antibodies for fluorescence microscopy, or using goat anti-rabbit gold (10-nm particles) for electron microscopy. Controls using preimmune serum, antiserum absorbed with excess synthetic peptide (as described above), or omission of primary or secondary antibody revealed no labeling.

Quantification of AQP2 immunolabeling in inner medullary collecting duct cells. Electron micrographs were taken on a Philips 208 electron microscope, covering the entire area of principal cells, and printed at a final magnification of 37,500. Gold particles associated with the apical and basolateral plasma membranes, and intracellular vesicles, were counted. The linear labeling density of apical plasma membrane was determined as the number of gold particles per micron of apical plasma membrane, and cell area (excluding nuclei) was calculated in square microns. A computerized digitizing tablet was used to measure length and area (resolution $<4 \mathrm{~nm}$ ).

Statistics. For densitometry of immunoblots, four or five samples from lithium-treated animals were run on each gel with four or three representative controls, respectively. AQP2 labeling in the samples from lithium-treated animal was calculated as a fraction of the mean control a
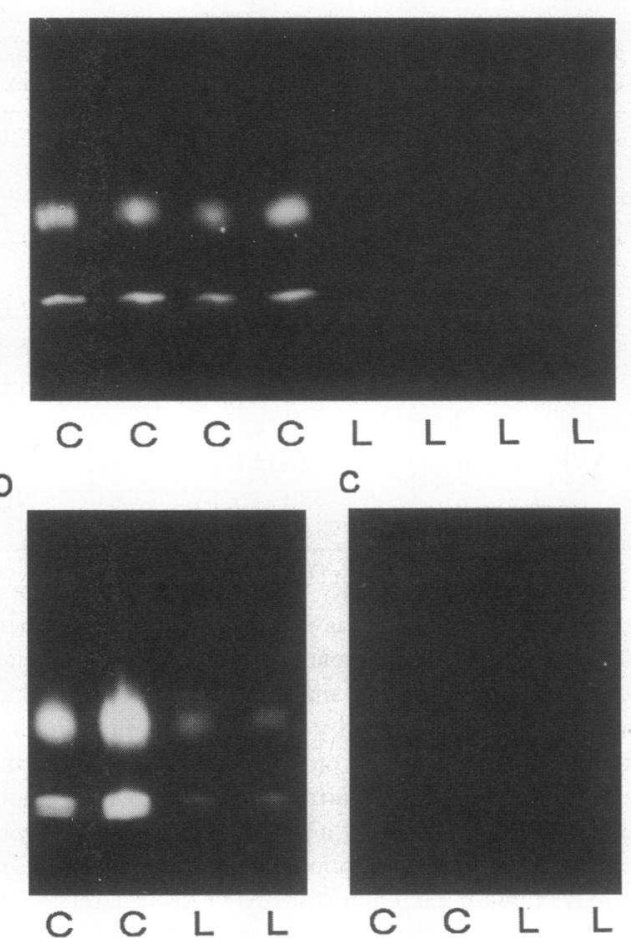

Figure 2. Immunoblots comparing AQP2 expression in four control rats $(C)$ and four rats treated with lithium for $25 \mathrm{~d}(L)$. (a) Lithium caused a dramatic decrease in AQP2 levels, although some expression $(b)$ can still be detected by prolonged exposure of the detection films. $(c)$ No signal was seen if the primary antibody was preabsorbed with the immunizing peptide.

value for that gel. Values are presented in the text as means \pm standard errors. Comparisons between groups were made by unpaired $t$ test.

\section{Results}

Lithium reduces $A Q P 2$ expression. Lithium therapy reduced AQP2 expression dramatically. Fig. $2 a$ compares the expression of AQP2 in rat inner medullary crude membranes obtained from four control rats with that from four rats treated with lithium for $25 \mathrm{~d}$. Prominent bands at 29 and 35-45 $\mathrm{kD}$ were seen in the controls, representing the nonglycosylated and glycosylated forms of $\operatorname{AQP2}(9,10)$, respectively. Due to the reduced expression, the bands were very faint in the samples from lithium-treated rats, although they could be visualized after prolonged exposure of the ECL film (Fig. $2 b$ ). This revealed 29- and 35-45-kD bands identical to those seen in the controls. There were no detectable differences in the relative contribution of glycosylated and nonglycosylated AQP2 between controls and lithium-treated animals. The specificity of the labeling was ascertained by use of antibody preabsorbed with excess of peptide, which ablated the bands (Fig. $2 c$ ). In addition to the 29and $35-45-\mathrm{kD}$ bands, a further band migrating at $17 \mathrm{kD}$ was occasionally seen, and this band represented a greater fraction of labeling in the samples from lithium-treated animals (e.g., Fig. 6). This $17-\mathrm{kD}$ band probably represents partially degraded AQP2 (18), in agreement with the detection of low molecular weight AQP2 fragments in urine (19). 

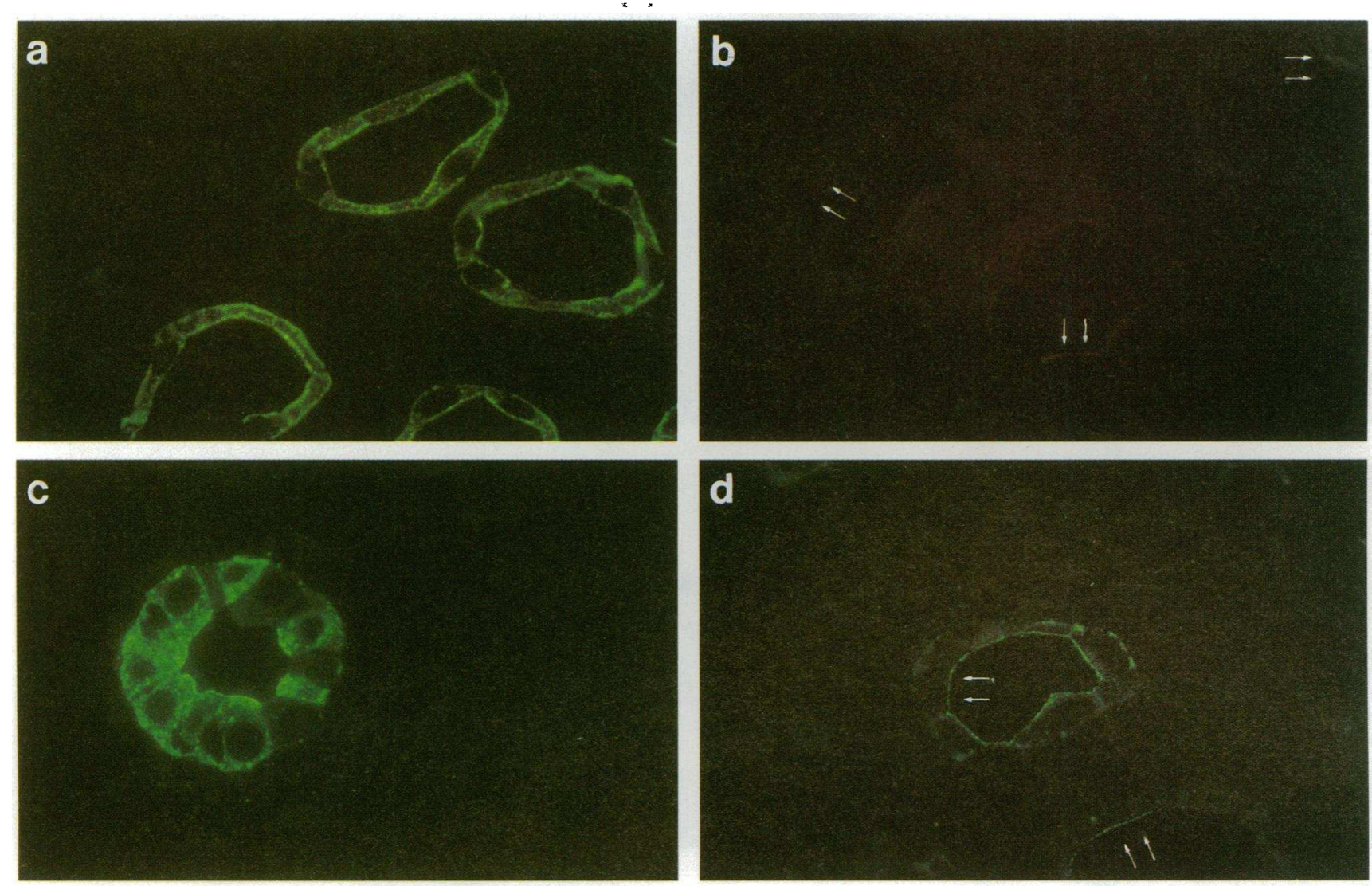

Figure 3. Immunofluorescent localization of AQP2 in cryosections of kidney inner medulla. ( $a$ ) In control rats, collecting ducts labeled prominently with antibodies against AQP2. No other structures were labeled. (b) After lithium treatment, only traces of labeling remained. (c) Thirsting for 48 $\mathrm{h}$ in the continued presence of lithium increased expression relative to lithium alone, but levels are still lower than seen in controls. Labeling was widely distributed throughout the cells. $(d)$ After $7 \mathrm{~d}$ of dDAVP treatment in the continued presence of lithium, there was some increase in labeling, which was concentrated very close to the apical surface of the cells. $\times 840$.

The immunoblotting densitometry data are summarized in Table I. After $10 \mathrm{~d}$, lithium-treated animals expressed only $31 \%$ of the AQP2 seen in controls $(n=10, P<0.01)$. By $25 \mathrm{~d}$ this had decreased to $4 \%(n=9, P<0.01)$, and no further significant change was seen after $35 \mathrm{~d}$ of treatment (Table I).

Immunocytochemistry using immunofluorescence (Fig. 3) or immunogold electron microscopy (Fig. 4) revealed markedly reduced AQP2 labeling of inner medullary collecting duct principal cells. In contrast, no equivalent change occurs in the expression of AQP1 in descending thin limbs (not shown). In control animals, the apical plasma membrane of these cells displayed heavy labeling, and moderate labeling of vesicles throughout the cytoplasm and of the basolateral plasma membrane were also observed (Figs. $3 a$ and $4 a$ ). In contrast, intercalated cells were unlabeled.

To evaluate further the downregulation of AQP2, the AQP2 immunogold labeling of inner medullary collecting duct principal cells was quantitated using electron microscopy. After 25 $\mathrm{d}$ of lithium treatment, labeling was reduced to $9 \%$ of the control level, consistent with the results obtained by immunoblotting (Tables I and II).

Recovery of $A Q P 2$ expression is slow. After $35 \mathrm{~d}$ of treatment with lithium, rats were returned to a normal diet, without lithium, for $7 \mathrm{~d}$. This resulted in an increase of about fourfold in urine osmolality, which was paralleled by a similar increase in AQP2 expression (Table I).
Consistent with the known large variation in urine osmolality in normal rats (20), the urine osmolalities measured after cessation of lithium treatment were not significantly different from the controls. However, the mean value was only two thirds of that seen in the controls. This is consistent with the change in AQP2 expression, which increased only to $40 \%$ of control ( $n=5, P<0.05)$, revealing an incomplete recovery of expression after $7 \mathrm{~d}$ (Fig. 5).

Thirsting and dDAVP treatment partially reverse downregulation. Thirsting for $48 \mathrm{~h}$, during the continued administration of lithium, caused a fourfold increase in urine osmolality and a parallel increase in AQP2 expression to 5.6 times lithiumtreated level, as assessed by comparison of samples from thirsted rats with those from lithium-treated animals run on the same gels (Fig. $6 a$ ). When compared directly with controls, the level in thirsted rats averaged $45 \%(P<0.05)$ (see Table I and Fig. $6 c$ ). The increase in expression induced by thirsting was confirmed by quantitative immunocytochemistry, corresponding to 4.8 times $(P<0.01)$ the lithium-treated level (compare also Fig. 3, $b$ and $c$ ).

Treatment with intravenous dDAVP for $7 \mathrm{~d}$ also caused a substantial increase in urine osmolality (Table I), as previously described (21), and a relatively modest increase in AQP2 expression. When determined by immunoblotting and densitometry, assessed by direct comparison of samples from dDAVPtreated and lithium-treated rats on the same gels, the increase 

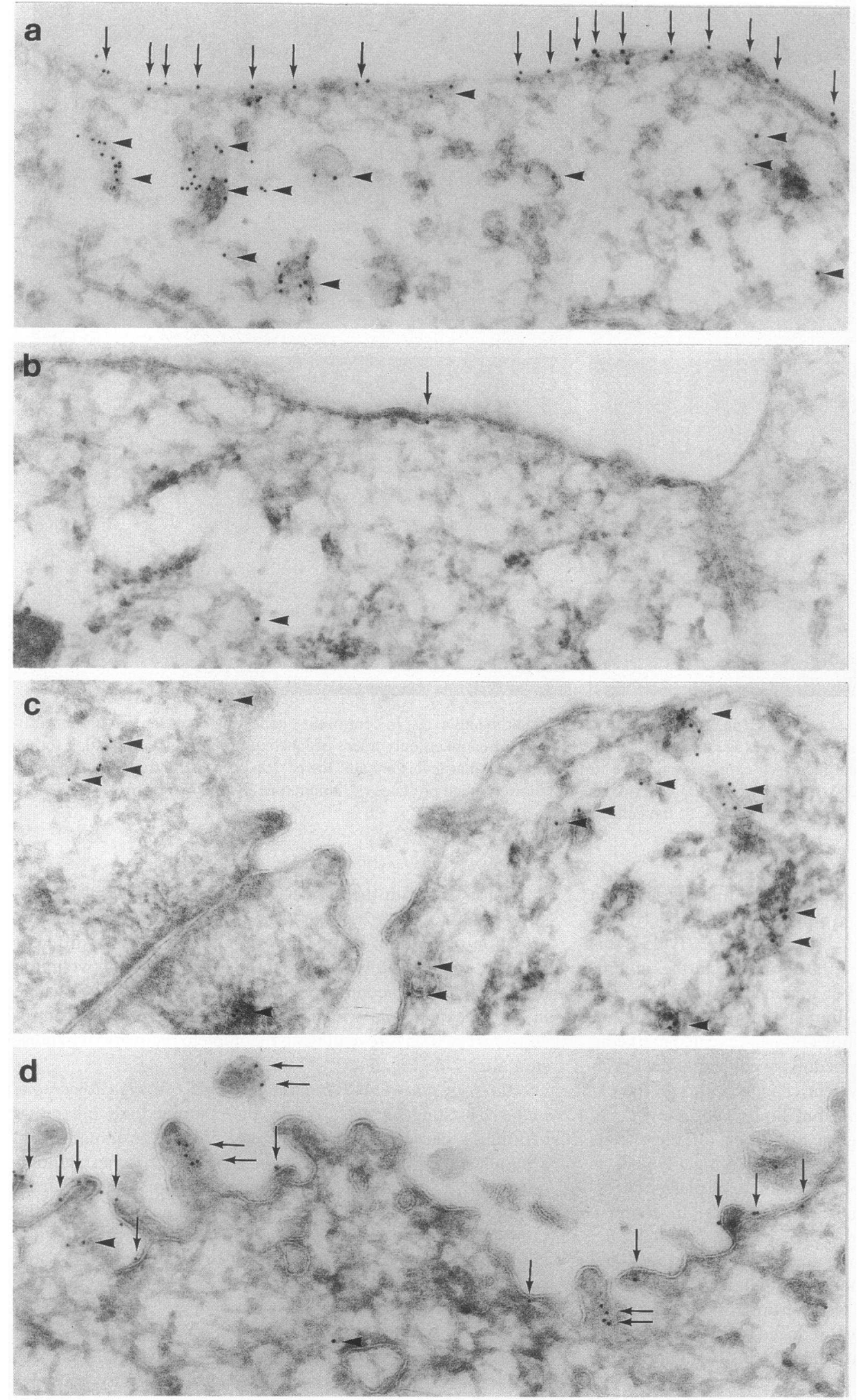

Figure 4. Immunoelectron micrographs of inner medullary collecting ducts labeled for AQP2. (a) In control rats, heavy labeling of both apical plasma membrane (arrows) and intracellular vesicles (arrowheads) can be seen (b) In lithium-treated animals labeling is extremely sparse. $(c)$ Thirsting for $48 \mathrm{~h}$ causes a dramatic relative increase in AQP2 labeling, with most labeling being of intracellular structures (arrowheads). (d) After dDAVP treatment of lithium-treated animals, there is significantly increased labeling, which is confined primarily to the apical plasma membrane (arrows). 
Table II. Quantitation of Immunogold Labeling of AQP2 in Inner Medullary Collecting Ducts

\begin{tabular}{|c|c|c|c|c|c|c|c|c|c|}
\hline \multirow[b]{2}{*}{ Treatment } & \multirow[b]{2}{*}{$n^{*}$} & \multicolumn{4}{|c|}{ Number of gold particles ${ }^{\ddagger}$} & \multirow[b]{2}{*}{ Length } & \multirow[b]{2}{*}{ Area } & \multirow{2}{*}{$\begin{array}{l}\text { Apical plasma } \\
\text { membrane } \\
\text { linear labeling } \\
\text { density }\end{array}$} & \multirow{2}{*}{$\begin{array}{l}\text { Total cell } \\
\text { labeling } \\
\text { density }\end{array}$} \\
\hline & & Apical & Intracellular & Basolateral & Total & & & & \\
\hline & & & & & & $\mu m$ & $\mu m^{2}$ & particles/um & particles/ $\mu m^{2}$ \\
\hline Control & 4 & 1071 & 3133 & 200 & 4404 & 201 & 389 & $5.3 \pm 0.4$ & $11.2 \pm 1.0$ \\
\hline Lithium (25 d) & 3 & 52 & 280 & 68 & 400 & 110 & 374 & $0.4 \pm 0.2$ & $1.1 \pm 0.2$ \\
\hline Thirsted for $48 \mathrm{~h}$ & 4 & 74 & 2050 & 280 & 2404 & 90 & 447 & $0.9 \pm 0.2$ & $5.1 \pm 0.8$ \\
\hline $\mathrm{dDAVP}$ for $7 \mathrm{~d}$ & 3 & 410 & 705 & 191 & 1306 & 211 & 399 & $1.9 \pm 0.2$ & $2.1 \pm 0.1$ \\
\hline
\end{tabular}

These results confirm the immunofluorescence observations. Lithium therapy causes a dramatic decrease in AQP2 expression, which is partially reversed by thirsting or dDAVP. While thirsting causes a greater increase in total expression, dDAVP is more effective at increasing apical labeling. * Number of experimental animals. ${ }^{\ddagger}$ Number of gold particles in apical plasma membrane, intracellular vesicles, and basolateral membrane, summed from all animals.

in AQP2 expression averaged 3.4 times $(P<0.01)$ the lithiumtreated level. When compared directly with untreated controls, AQP2 levels in dDAVP-treated animals averaged only $11 \%(P$ $<0.001$ ) of control values (Fig. $6, b$ and $c$ ). Consistent with this, immunogold labeling revealed a twofold $(P<0.01)$ increase in AQP2 expression after dDAVP treatment, corresponding to $19 \%(P<0.01)$ of the labeling in controls (Table II). However, the dDAVP-induced increase in AQP2 expression was less marked than that seen after thirsting.

Changes in subcellular distribution of AQP2. In controls, immunofluorescence and immunoelectron microscopy showed heavy labeling of the apical region of inner medullary collecting duct cells, with considerable punctate labeling present in the cytoplasm (Figs. $3 a$ and $4 a$ ). Basolateral membranes labeled only to a lesser degree. After lithium treatment, AQP2 labeling was almost completely absent (Figs. $3 b$ and $4 b$ ), confirming the extensive downregulation of AQP2 expression. Consistent with the results of immunoblotting, thirsting induced a substantial increase in labeling. The labeling was mainly distributed in vesicles scattered throughout the cytoplasm (Figs. $3 c$ and 4 c). Similarly, dDAVP treatment also induced an increase in AQP2 labeling, albeit to a lesser extent. The labeling was concentrated in the extreme apical part of the cells (Figs. $3 d$ and $4 d)$.

Fig. 7 summarizes the morphometric analysis of the subcellular distribution of AQP2. An analysis of the labeling density of the apical plasma membrane (Fig. $7 \mathrm{~B}$ ) revealed a marked decrease after lithium treatment. After dDAVP treatment there was a substantial increase in apical labeling, despite the rather modest increase in AQP2 expression. Conversely, thirsting caused little increase in apical plasma membrane labeling, de-

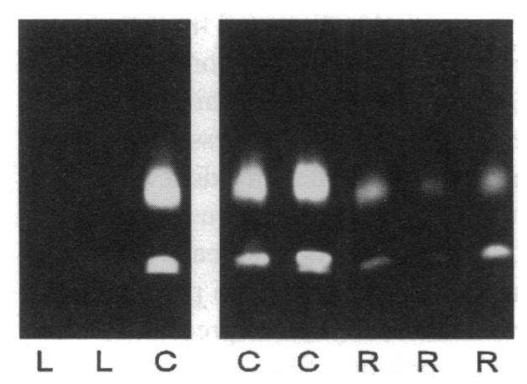

Figure 5. Immunoblots comparing $\mathrm{AQP2}$ levels in inner medulla after 1 wk return to normal diet $(R)$ with lithium-treated $(L)$ and control $(C)$ animals. Expression after return to lithium-free diet was still well below control levels, but substantially above that in lithium-treated animals. spite the fivefold increase in total AQP2 labeling. This is even more prominent .when apical AQP2 labeling is expressed as a fraction of total (Fig. $7 C$ ), which provides further evidence that dDAVP caused a marked increase in apical plasma membrane labeling, while thirsting was unable to cause such an increase.

\section{Discussion}

This study demonstrates that chronic lithium treatment results in a downregulation of AQP2 water channel expression in rat inner medulla, concurrent with the development of severe polyuria. The reduction in AQP2 expression can be partly reversed by thirsting or exogenous dDAVP, but spontaneous recovery of AQP2 expression after cessation of lithium treatment occurs only slowly. The modulation of AQP2 expression may represent a means of long-term regulation of antidiuresis and raises the possibility that other forms of NDI may be at least partly due to a reduction in the availability of AQP2 water channels.

$N D I$ and reduced expression of $A Q P 2$. It is well established that lithium often causes a vasopressin-resistant urinary concentrating defect, i.e., NDI $(2,3)$, associated with structural changes in the medullary collecting ducts $(22)$ and that the rat provides a useful animal model of this $(5,23)$. Our results demonstrate that lithium-induced diuresis is associated with a dramatic decrease in AQP2 in collecting ducts, which may be a factor in the severity of the polyuria, as it has been shown that the absence of functional AQP2 causes profound NDI (14). It will be of interest to determine whether other forms of acquired NDI are also associated with decreased expression or delivery of AQP2 to the plasma membrane. Other, non-druginduced forms of acquired NDI, including those caused by electrolyte disturbances (e.g., hypokalemia and hypercalcemia), certain systemic disorders, and post-obstructive or osmotic diuresis (15), may also be associated with changes in AQP2 levels. Preliminary evidence indicates that rats with polyuria associated with hypokalemia (Marples, D., and S. Nielsen, unpublished observations) or ureteric obstruction (Frøkjær, J., D. Marples, and S. Nielsen, unpublished observations) also have reduced AQP2 levels, supporting the view that reduced AQP2 expression may be a factor in NDI from a variety of causes.

Recovery from lithium-induced NDI. Clinical studies have shown that many patients take several weeks to regain their normal urinary concentrating ability after cessation of chronic 
a
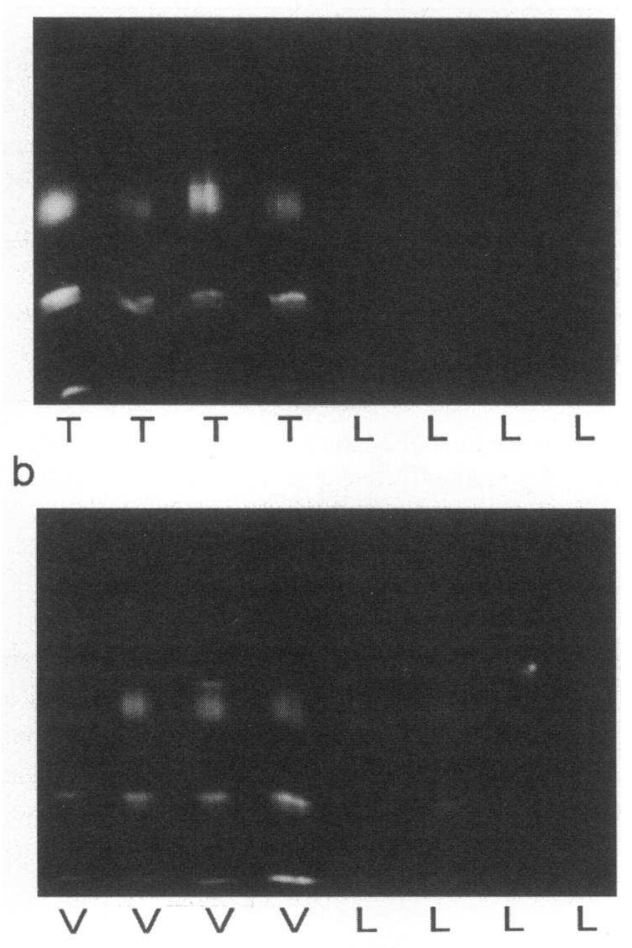

C

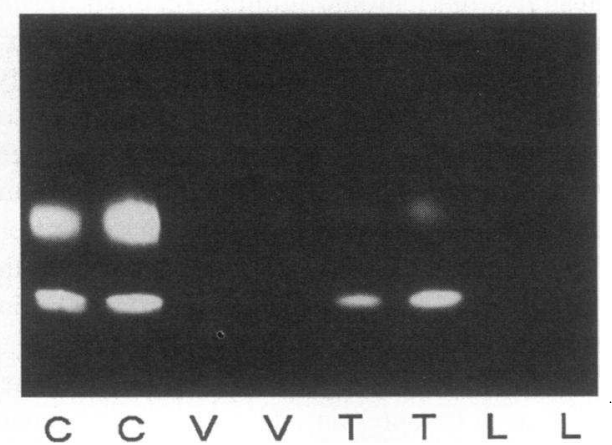

Figure 6. Immunoblots comparing AQP2 expression in inner medulla of lithium-treated rats $(L)$ with $(a)$ lithium-treated rats either thirsted for $48 \mathrm{~h}(T)$ or $(b)$ infused with dDAVP for $7 \mathrm{~d}(V)$. Both cause an increase in expression. However, $(c)$ levels were considerably higher in thirsted than in dDAVP-treated rats, but neither was as high as that seen in control rats $(C)$.

lithium therapy (3), and similar observations have been made in rats (24). Our finding that AQP2 levels remain well below control levels even a week after removal of lithium from the diet suggests that the prolonged concentrating defect may be a consequence of a slow recovery in the expression of water channels. It is also known that recovery from a number of other disorders of urinary concentrating ability, including those described above and that induced by compulsive polydipsia (25), lags significantly behind the correction of the underlying electrolyte disturbance. This may also reflect a slow recovery in AQP2 water channel expression.

In contrast to the process of spontaneous recovery after a downregulation of expression, which appears to be a slow process (Table I), upregulation in response to a stimulus, such as
A Total AQP2 Immunogold Labeling in Principal Cells

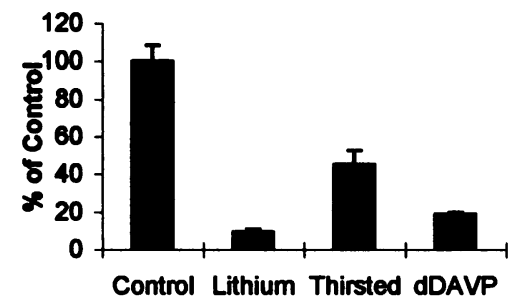

\section{B}
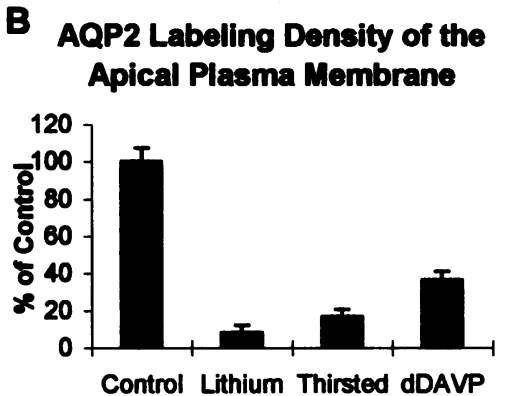

\section{C}

\section{Apical AQP2 Labeling as a Fraction of total Labeling}

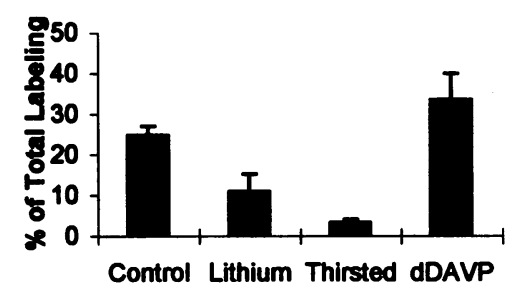

Figure 7. Quantitation of immunogold labeling for AQP2 in principal cells of inner medullary collecting ducts. $A$ shows the dramatic decrease in total AQP2 labeling density caused by lithium treatment for $25 \mathrm{~d}$ and the partial recovery in response to thirsting ( $48 \mathrm{~h}$ ) or dDAVP ( $7 \mathrm{~d})$. (B)

Similar changes are seen in labeling of the apical plasma membrane.

Whereas thirsting caused a greater increase in overall AQP2 expression, dDAVP induced a greater increase in apical labeling. This is emphasized in $C$, which shows apical labeling as a fraction of total labeling. dDAVP-treated rats, despite the continued presence of lithium, have a higher percentage of their $\mathrm{AQP2}$ associated with the apical plasma membrane than even controls. Conversely, the fraction of water channels in the apical plasma membrane is not increased by thirsting.

thirsting, occurs within 1-2 d in lithium-treated (Table I) and normal rats (10). Our finding that thirsting for $2 \mathrm{~d}$ in lithiumtreated rats induced a substantial increase in expression suggests that this rapid induction in response to a stimulus can still occur despite continued lithium therapy. However, expression after thirsting is still below control levels, presumably reflecting a continued effect of lithium.

Thirsting- and dDAVP-induced increased in AQP2 expression. In addition to the increase in the number of functional water channels in the apical plasma membrane induced acutely by vasopressin (26), it has been shown recently that chronic treatment with exogenous vasopressin causes an increase in AQP2 expression in Brattleboro rats (13). Furthermore, isolated perfused inner medullary collecting ducts dissected from such vasopressin-treated Brattleboro rats display a threefold higher water permeability than tubules dissected from untreated rats (13). In addition, prolonged thirsting of normal rats also induces an increase in AQP2 expression (10), while water loading decreases AQP2 levels (10). Thus vasopressin also plays a long-term role in the regulation of collecting duct water permeability by modulating the level of AQP2 expression. Consistent with this hypothesis, thirsting did not increase AQP2 expression in Brattleboro rats, which are unable to produce vasopressin (27). Furthermore, Brattleboro rats express only a low level of AQP2 under normal conditions. Since lithium has been 
shown to inhibit the increase in cAMP caused by vasopressin $(2,3,5)$, the block of vasopressin action could provide a mechanism for the reduction of AQP2 expression seen after lithium treatment. This reduction may in turn be a significant component of the lithium-induced NDI.

Despite the ability of dDAVP to increase urine osmolality and apical plasma membrane AQP2 labeling, treatment with dDAVP (which is a specific $V_{2}$ agonist) produced only a small increase in AQP2 expression. Consistent with this, it has previously been found that lithium-induced diabetes insipidus is unresponsive to exogenous vasopressin, but can be treated with dDAVP (28), which can be used at much higher doses because of its lack of pressor activity (21). The present results suggest that the antidiuretic activity of dDAVP is largely due to its ability to overcome the block of adenylate cyclase caused by lithium, as it causes relocation of AQP2 to the extreme apical part of the cell, and presumably induction of water channel insertion into the plasma membrane, as previously described in normal rats $(11,12)$.

Of interest, thirsting induced a considerably greater increase in expression of AQP2 than treatment with dDAVP. However, thirsting failed to induce significant redistribution of AQP2 labeling and hence appears to have been less effective than dDAVP in overcoming the block of the water channel delivery process. This raises the possibility that the mechanism for AQP2 induction by thirsting may differ from that involved in causing water channel delivery to the plasma membrane.

Summary. In summary, our results demonstrate that chronic lithium treatment of rats causes a substantial decrease in AQP2 expression in medullary collecting ducts, in conjunction with a decline in urinary osmolality and increasing polydipsia and polyuria. This decrease is only partially reversed 1 wk after cessation of lithium treatment, consistent with clinical findings of a slow recovery of urinary concentrating ability after prolonged lithium therapy.

\section{Acknowledgments}

The authors thank Hanne Sidelmann and Inger Kristoffersen for excellent technical assistance.

Support for this study was provided by the Novo Nordisk Foundation, The Danish Research Academy, The Danish Medical Research Council, University of Aarhus Research Foundation, Danish Foundation for the Advancement of Medical Science, the Biomembrane Research Center at University of Aarhus, and the Aage Louis Hansen Foundation.

\section{References}

1. Peet, M., and J. P. Pratt. 1993. Lithium. Current status in psychiatric disorders. Drugs. 46:7-17.

2. Christensen, S. 1988. Vasopressin and renal concentrating ability. In Lithium Therapy Monographs, vol. 2. F. N. Johnson, editor. S. Karger AG, Basel. 20-34.

3. Boton, R., M. Gaviria, and D. C. Batlle. 1987. Prevalence, pathogenesis, and treatment of renal dysfunction associated with chronic lithium therapy. Am. J. Kidney Dis. 10:329-345. S98.

4. Walker, R. G. 1993. Lithium nephrotoxicity. Kidney Int. Suppl. 42:S93-

5. Christensen, S., E. Kusano, A. N. Yusufi, N. Murayama, and T. P. Dousa. 1985. Pathogenesis of nephrogenic diabetes insipidus due to chronic administration of lithium in rats. J. Clin. Invest. 75:1869-1879.

6. Sugawara, M., K. Hashimoto, and Z. Ota. 1988. Involvement of prostaglan- din E2, cAMP, and vasopressin in lithium-induced polyuria. Am. J. Physiol. 254:R863-R869.

7. Yamaki, M., E. Kusano, T. Tetsuka, S. Takeda, S. Homma, N. Murayama and Y. Asano. 1991. Cellular mechanism of lithium-induced nephrogenic diabetes insipidus in rats. Am. J. Physiol. 261:F505-F511.

8. Agre, P., G. M. Preston, B. L. Smith, J. S. Jung, S. Raina, C. Moon, W. B. Guggino, and S. Nielsen. 1993. Aquaporin CHIP: the archetypal molecular water channel. Am. J. Physiol. 265:F463-F476.

9. Fushimi, K., S. Uchida, Y. Hara, Y. Hirata, F. Marumo, and S. Sasaki. 1993. Cloning and expression of apical membrane water channel of rat kidney collecting tubule. Nature (Lond.). 361:549-552.

10. Nielsen, S., S. R. DiGiovanni, E. I. Christensen, M. A. Knepper, and H. W. Harris. 1993. Cellular and subcellular immunolocalization of vasopressinregulated water channel in rat kidney. Proc. Natl. Acad. Sci. USA. 90:1166311667.

11. Nielsen, S., C. L. Chou, D. Marples, E. I. Christensen, B. K. Kishore, and M. A. Knepper. 1995. Vasopressin increases water permeability of kidney collecting duct by inducing translocation of aquaporin-CD water channels to plasma membrane. Proc. Natl. Acad. Sci. USA. In press.

12. Marples, D., M. A. Knepper, E. I. Christensen, and S. Nielsen. 1994. Vasopressin-induced redistribution of AQP-CD water channels in rat kidney inner medulla. J. Am. Soc. Nephrol. 5:275a. (Abstr.)

13. DiGiovanni, S. R., S. Nielsen, E. I. Christensen, and M. A. Knepper. 1994. Regulation of collecting duct water channel expression by vasopressin in Brattleboro rat. Proc. Natl. Acad. Sci. USA. 91:8984-8988.

14. Deen, P. M., M. A. Verdijk, N. V. Knoers, B. Wieringa, L. A. Monnens, C. H. van-Os, and B. A. van-Oost. 1994. Requirement of human renal water channel aquaporin-2 for vasopressin-dependent concentration of urine. Science (Wash. DC). 264:92-95.

15. Howard, R. L., D. G. Bichet, and R. W. Schrier. 1992. Hypernatremic and polyuric states. In The Kidney. Physiology and Pathophysiology. D. W. Seldin and G. Giebisch, editors. Raven Press, New York. 1753-1778.

16. Christensen, S., and T. Agner. 1982. Effects of lithium on circadian cycles in food and water intake, urinary concentration and body weight in rats. Physiol. \& Behav. 28:635-640.

17. Nielsen, S., B. Smith, E. I. Christensen, M. A. Knepper, and P. Agre 1993. CHIP28 water channels are localized in constitutively water-permeable segments of the nephron. J. Cell Biol. 120:371-383.

18. Harris, H. W. J., M. L. Zeidel, I. Jo, and T. G. Hammond. 1994. Characterization of purified endosomes containing the antidiuretic hormone-sensitive water channel from rat renal papilla. J. Biol. Chem. 269:11993-12000.

19. Sasaki, S., K. Fushimi, H. Saito, F. Saito, S. Uchida, K. Ishibashi, M Kuwahara, T. Ikeuchi, K. Inui, K. Nakajima, et al. 1994. Cloning, characterization, and chromosomal mapping of human aquaporin of collecting duct. J. Clin. Invest. 93:1250-1256.

20. Lankford, S. P., C. L. Chou, Y. Terada, S. M. Wall, J. B. Wade, and M. A. Knepper. 1991. Regulation of collecting duct water permeability independent of cAMP-mediated AVP response. Am. J. Physiol. 261:F554-F566.

21. Christensen, S. 1980. DDAVP (1-desamino-8-D-arginine-vasopressin) treatment of lithium-induced polyuria in the rat. Scand. J. Clin. Lab. Invest. 40:151-157

22. Ottosen, P. D., N. O. Jacobsen, and S. Christensen. 1992. Morphological and enzyme histochemical changes induced by lithium in laboratory animals. In Lithium Therapy Monographs, vol. 13. F. N. Johnson, editor. S. Karger AG, Basel. 82-94.

23. Christensen, S. 1976. Acute and chronic effects of vasopressin in rats with lithium-polyuria. Acta Pharmacol. et Toxicol. 38:241-253.

24. Christensen, S., B. B. Hansen, and P. Faarup. 1982. Functional and structural changes in the rat kidney by long-term lithium treatment. Renal Physiol. 5:95-104.

25. Epstein, F. H., C. R. Kleeman, and A. Hendrikx. 1957. The influence of bodily hydration on the renal concentrating process. J. Clin. Invest. 36:629-634.

26. Knepper, M. A., and F. C. Rector, Jr. 1991. Urinary concentration and dilution. In The Kidney. Volume I. B. M. Brenner and F. C. Rector, Jr., editors. W. B. Saunders Co., Philadelphia/London. 445-482.

27. Chou, C. L., S. R. DiGiovanni, and M. A. Knepper. 1994. Hydro-osmotic action of oxytocin in terminal IMCD of Brattleboro rat. J. Am. Soc. Nephrol. 5:268a. (Abstr.)

28. Seif, S. M., T. V. Zenser, F. F. Ciarochi, B. B. Davis, and A. G. Robinson 1978. DDAVP (1-desamino-8-D-arginine-vasopressin) treatment of central diabetes insipidus: mechanism of prolonged antidiuresis. J. Clin. Endocrinol. \& Metab. 46:381-388.

29. Baldessarini, R. J. 1992. Drugs and the treatment of psychiatric disorders. In The Pharmacological Basis of Therapeutics. A. G. Gilman, T. W. Rall, A. S. Nies, and P. Taylor, editors. McGraw-Hill Inc., New York. 383-435.

30. Kirchner, K. A. 1990. Effect of diuretic and antidiuretic agents on lithium clearance as a marker for proximal delivery. Kidney Int. Suppl. 37:S22-S25. 